\title{
Efficiency improvement in redundant power systems by means of thermal load sharing
}

\section{Nesgaard, Carsten; Andersen, Michael Andreas E.}

\section{Published in:}

APEC 2004 - Nineteenth Annual IEEE Applied Power Electronics

Link to article, DOI:

10.1109/APEC.2004.1295845

Publication date:

2004

Document Version

Publisher's PDF, also known as Version of record

Link back to DTU Orbit

\section{Citation (APA):}

Nesgaard, C., \& Andersen, M. A. E. (2004). Efficiency improvement in redundant power systems by means of thermal load sharing. In APEC 2004 - Nineteenth Annual IEEE Applied Power Electronics (Vol. 1, pp. 433-442). IEEE. https://doi.org/10.1109/APEC.2004.1295845

\section{General rights}

Copyright and moral rights for the publications made accessible in the public portal are retained by the authors and/or other copyright owners and it is a condition of accessing publications that users recognise and abide by the legal requirements associated with these rights.

- Users may download and print one copy of any publication from the public portal for the purpose of private study or research.

- You may not further distribute the material or use it for any profit-making activity or commercial gain

- You may freely distribute the URL identifying the publication in the public portal 


\section{Efficiency improvement in redundant power systems by means of thermal load sharing}

\author{
Carsten Nesgaard \\ Oersted-DTU, Automation \\ DK-2800 Kongens Lyngby \\ Technical University of Denmark \\ Email: $\underline{\text { cn@oersted.dtu.dk }}$
}

\author{
Michael A. E. Andersen \\ Oersted-DTU, Automation \\ DK-2800 Kongens Lyngby \\ Technical University of Denmark \\ Email: $\underline{\text { ma@oersted.dtu.dk }}$
}

\begin{abstract}
The demand for higher output currents at ever lower voltage levels is often solved by paralleling multiple converters. Provided redundancy is implemented this technique, besides being relatively easy to implement, has the advantage of improving the overall system reliability. Also, the parallel-connection concept forms the basis of a very cost-effective power system design, since the entire system often can be realized using off-the-shelf units. This paper verifies experimentally that the use of the thermal load sharing technique, proposed in [1], not only increases the overall system reliability but also has a positive impact on the system efficiency. The latter aspect is achieved by redistributing the current throughput of each converter, which in turn results in equal thermal conditions as opposed to the current sharing technique's intent to establish equal currents.
\end{abstract}

\section{INTRODUCTION}

This paper describes the experimental results of the new thermal load sharing technique presented in [1]. From a schematic presenting all key components in the test setup to measurements of load sharing currents and overall system efficiency this paper will verify that thermal load sharing in most cases outperforms the widely used current sharing technique.

The power system under consideration in [1] is comprised of 3 parallel-connected converter units. The theoretical results indicate that the new load sharing technique increases the overall system reliability quite significantly based on an unequal distribution of the individual converter load currents. From the description in [1] it can be deduced that the more converter units making up the power system the better results concerning reliability is achievable. From a system point of view this result seems obvious since the more paths the current can take from input to output the easier it is for the system to optimize the system temperatures by balancing the currents through each converter unit.

The system considered in this paper is comprised of 2 identical parallel-connected converter units, for which reason it should be expected that the overall reliability improvement is less than that found in [1]. Indeed, as the experimental verification will show the overall system improvement in terms of reliability and efficiency is less than that obtained in [1]. However, the results obtained still provide significant improvements in overall system performance. An analytic as well as verbal explanation of these results is provided in section "IV. THEORETICAL SYSTEM EVALUATION".

Finally, based on reliability calculations, presented in section "V. RELIABILITY ASSESSMENT", it will become clear that the use of thermal load sharing increases the overall system reliability by lowering the average system operating temperature.

\section{THE TEST SYSTEM}

The test system is comprised of 2 parallel-connected buck converters each capable of supplying a load current of $25 \mathrm{~A}$ at an output voltage of $5 \mathrm{~V}$. A block diagram of the two-converter system can be seen in Figure 1.

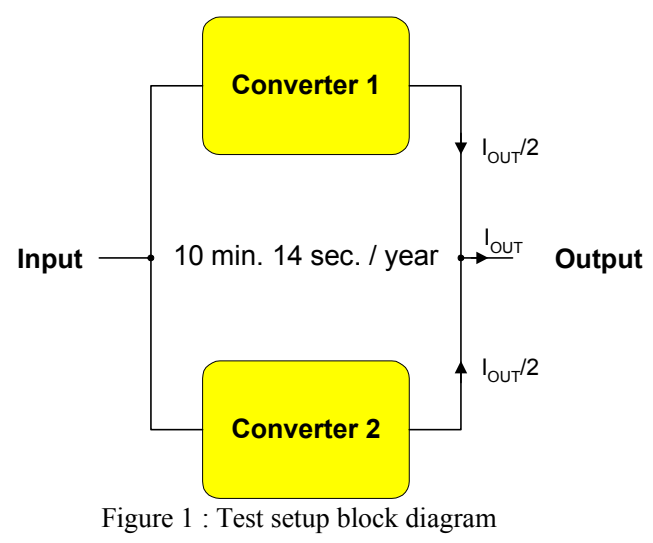

The annual downtime for the two-converter system, shown in Figure 1, utilizing the traditional current sharing technique can be calculated to 10 minutes and 14 seconds. This downtime is one of the parameters used to compare the two load sharing techniques. A description of the steps involved in calculating this downtime is presented in section "V. RELIABILITY ASSESSMENT".

Turning the attention towards a more detailed system outline, Figure 2 shows a simplified schematic of the test setup under consideration. Each converter utilizes 4 IC's, a single MOSFET transistor and two free-wheeling diodes. The reason for explicitly mentioning these active components is due to the fact that they are major contributors to the overall converter failure rate. Besides from these active components the converters are comprised of input- and output capacitors, the 
energy storing inductors and a relatively large number of small-signal components (not included in Figure 2).

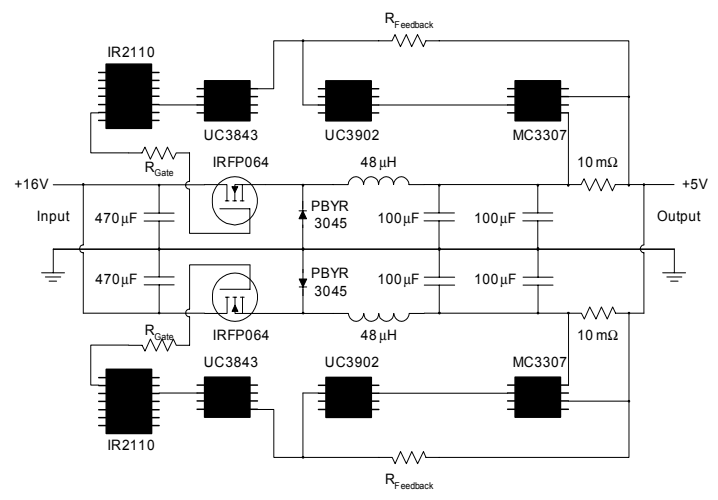

Figure 2 : Simplified schematic

The switching frequency, which was chosen to $122 \mathrm{kHz}$, results in an inductor ripple of approximately $0.6 \mathrm{~A}$.

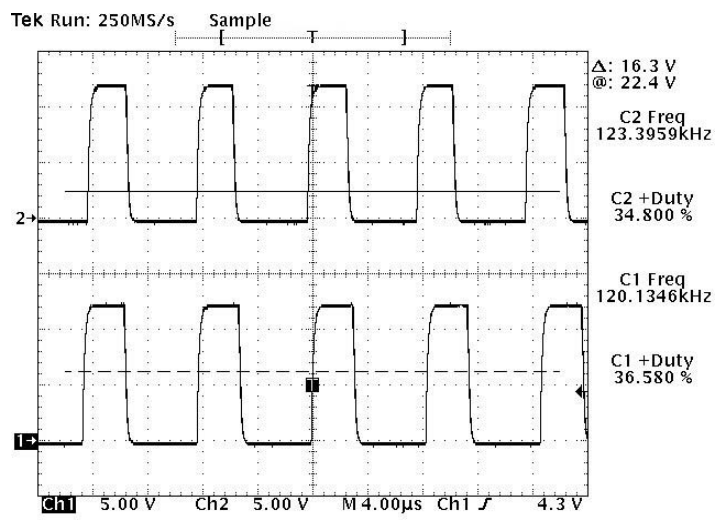

Figure 3 : Differential gate-source voltage for each converter

Even though every attempt has been made to ensure equal converter layout, performance and switching Figure 3 clearly shows that small differences exists. The timing problem is easily fixed by utilizing clock synchronization (however, the UC3843 has no sync pin) while the difference in duty cycle is intentional, since this determines the current supplied by each converter. It is estimated that the difference in switching frequency is relativity unimportant in relation to testing the two load sharing techniques, hence further discussion of this topic is omitted.

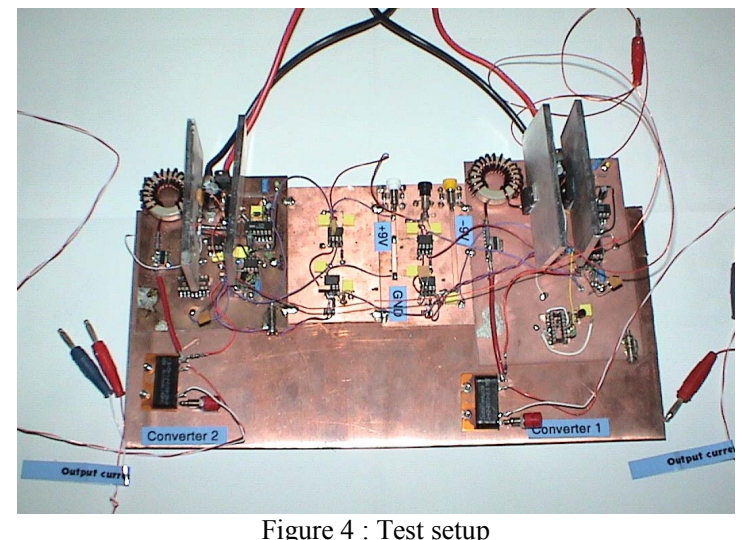

Figure 4 : Test setup
Figure 4 shows an image of the real-world test setup. The large copper baseplate on which the two converters are implemented is used as a heat stabilizing mechanism for all small-signal devices. The physical separation between the MOSFET transistor heatsinks $(24 \mathrm{~cm}$.) prevents the two converters from interacting thermally, thus increasing the adjustability of the control system.

\section{MEASUREMENTS AND SYSTEM DESCRIPTION}

Initially the two $25 \mathrm{~A}$ buck converters were paralleled and operated in a 'semi-droop' manner where the load sharing was based on the 'natural' output impedance of the converters. This technique is very simple but results unfortunately only in very rare situations in an acceptable performance, efficiency and reliability. Indeed, as the efficiency measurement shows one converter supplies almost the entire load current - leaving the other converter in an idle state. To optimize the efficiency and system reliability some form of load control is needed. The implementation of this concept is achieved by utilizing a dedicated load share controller. The load share controller used is the UC3902 from Texas Instruments. Since this controller does not allow for high-side differential current sensing an OPamp is employed to compensate for the lack of this feature. It should be noted that Texas Instruments do offer load share controllers that allows for high-side differential sensing (like the UC3907) but due to a rather tight schedule it was chosen to proceed with the load share controller available at the time of implementation - the UC3902.

Following the guidelines provided in the load share controller datasheet and associated application notes the current sharing technique was successfully implemented. The two buck converters were then operated at nominal output power $(12.5 \mathrm{~A}$ each) while tuning the current share controller. The result of this tuning can be seen in Figure 5.

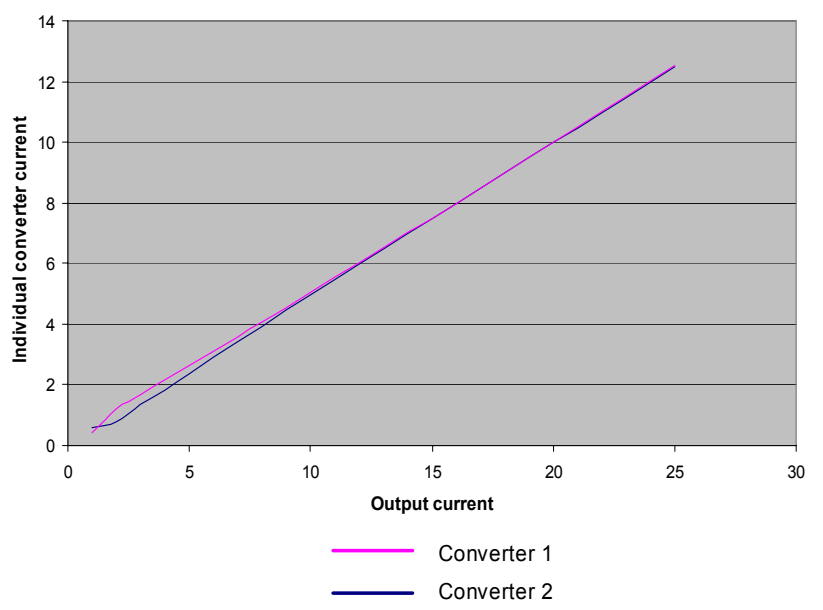

Figure 5 : Individual converter currents

Figure 5 shows that the achievable current sharing is very accurate. The only observable deviation from identical current levels is in the $1 \mathrm{~A}-7 \mathrm{~A}$ range. Since the load share controller operates over a fairly large current range a small deviation should be expected. 
The next set of measurements is performed while each converter operates individually, thus allowing for very accurate temperature data to be obtained. The result is shown in Figure 6.

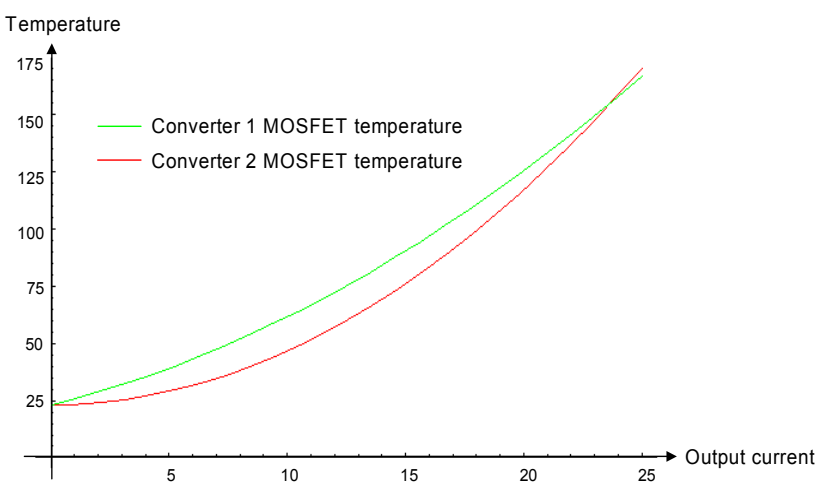

Figure 6 : MOSFET temperature measurements

The temperature at which the MOSFET transistors will be working is around $70^{\circ} \mathrm{C}$, since this temperature corresponds to an individual converter output current of 12.5A. From Figure 6 it can be seen that converter 1 generally operates at a higher temperature than converter 2 . The point where the temperatures of the two MOSFET transistors are equal is at an output current of 23.6A. Above this very high converter output current the temperature of the MOSFET transistor used in converter 2 exceeds the temperature of the MOSFET transistor used in converter 1. Part of the explanation for the relatively large MOSFET transistor temperature difference is shown in Figure 7, which shows the free-wheeling diode temperatures.

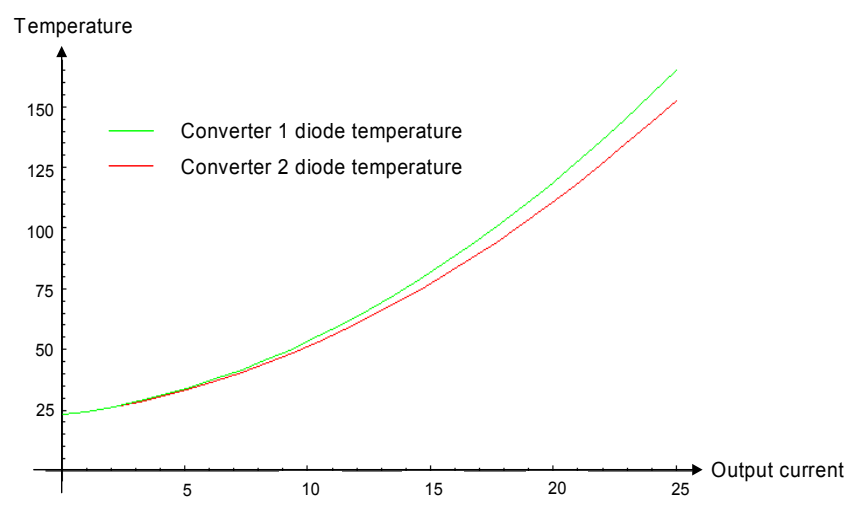

Figure 7 : Diode temperature measurements

The temperatures of the free-wheeling diodes are also relatively high. Again, it can be seen that converter 1 operates at a higher temperature than converter 2 . Since an intense mutual heating between the two active components takes place it is difficult to identify the actual self-heating of each component. As one component increases the ambient temperature (in the immediate vicinity of the power components) the other suffers from increases in parasitic elements resulting in increased internal heating. Some of the diode parameters that are affected thermal changes are described in section "IV. THEORETICAL SYSTEM EVALUATION".

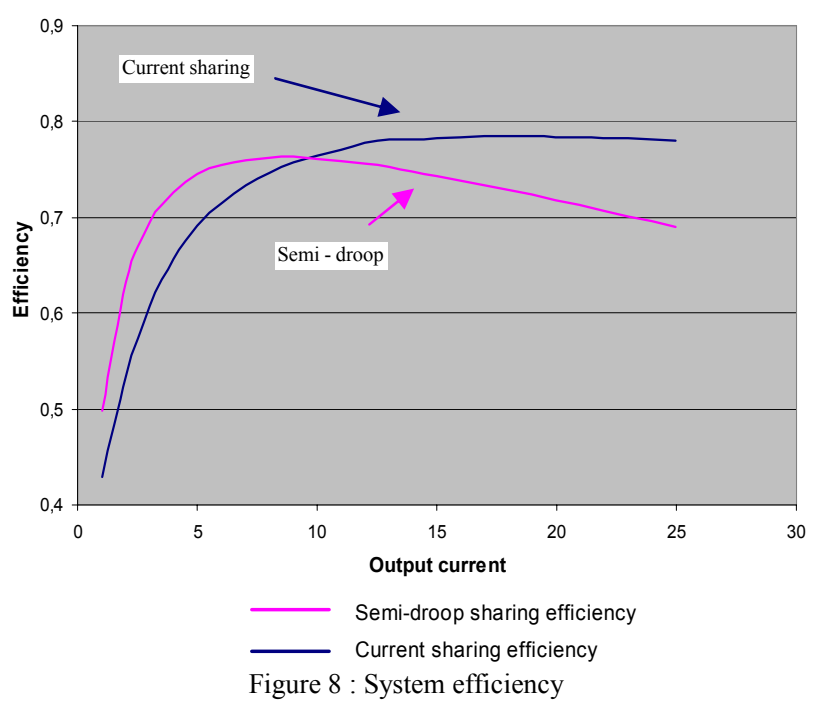

Figure 8 shows the efficiencies of the two techniques for parallel converter operation discussed so far. With reference to Figure 8 is can be seen that the semi-droop configuration exhibits higher efficiency at low output currents compared to the current sharing approach. This is simply due to chance since the converter supplying the majority of current in this test setup apparently has the highest output voltage (and efficiency at light loads). The control circuitry of the other converter monitors the common output voltage, which is higher than its internal reference voltage, and adjusts the duty cycle accordingly.

In order to make a fair comparison between the two load sharing techniques each converter is implemented with the exact same components, same length of wiring and current sensing resistors in both cases although not necessary in the thermal load sharing situation. Furthermore, since the thermal load sharing technique does not need high-side sensing the added OP-amp and associated passive components could also be removed from the circuit. However, for comparison purposes these components remain active during the thermal load sharing implementation.

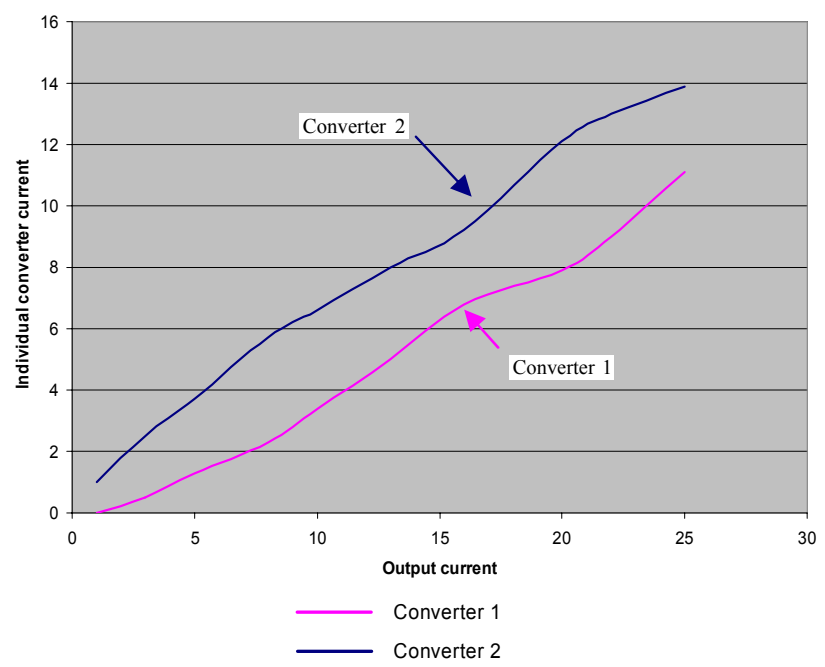

Figure 9 : Individual converter currents 
As can be seen in Figure 9 the individual converter currents are no longer identical - far from it actually. At lighter loads the difference between the two currents is $1 \mathrm{~A}$, but as the load increases the separation between the two converter currents become larger. At the nominal output current (25A) the difference between the two converter contributions is 3.1A. The system efficiency that results from this redistribution of converter currents can be seen in Figure 10.

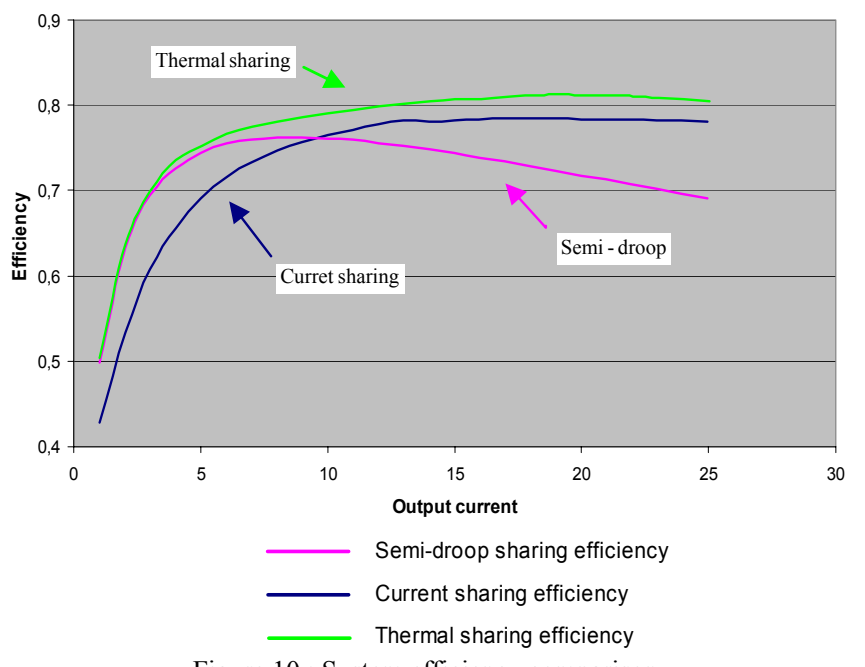

Figure 10 : System efficiency comparison

It should be noted that the efficiency of the thermal load sharing follows that of the semi-droop, since this causes the lowest system heating. At heavier loads the efficiency of the thermal load sharing exceeds that of the current sharing approach by approximately $2 \%$.

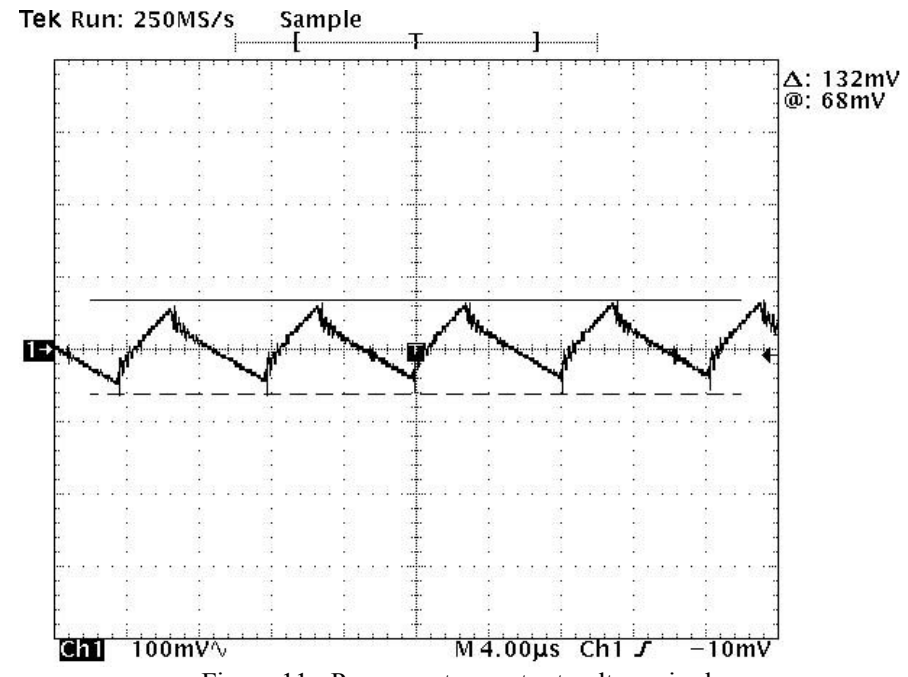

Figure 11 : Power system output voltage ripple

From Figure 11 it can be seen that the output voltage ripple deviates slightly from the expected triangular waveform. This is due to the small difference in switching frequency and the constant altered duty cycle. However, the ripple voltage is clearly within the $\pm 5 \%$ voltage variation limit set as a requirement for the power system under consideration.

\section{THEORETICAL SYSTEM EVALUATION}

This section explains why the current distribution of the thermal load sharing technique results in higher overall efficiency. The calculations will be limited to include only high power components - meaning, components that are related to the high current path from input to output. Identifying these components the following list can be established:

\section{- MOSFET transistors \\ - Free-wheeling diodes \\ - Current measurement resistors \\ - Inductors \\ - Capacitors}

Based on the subsequent descriptions and computations loss estimations are provided at the end of each subsection. These loss estimations verify that a shift in individual converter currents gives rise to the efficiency gain predicted in [1]. It should be noted that the correlation between output current, temperature and power losses in some of the power components is very complex. Due to this complexity the following descriptions only state the initial loss equations or make a reference to where the equations can be found otherwise than that the results are shown in terms of graphical illustrations.

\section{MOSFET transistors}

The redistribution of MOSFET transistor losses is the dominant factor in the system efficiency improvement. However, as will be shown the free-wheeling diodes and the filter capacitors also contribute to a shift in system losses whereas the contributions from the current measurement resistors and the inductors are only minor.

In the following section the subscript 'Current' is used to denote the losses associated with current sharing technique while the subscript 'Thermal' is used to denote the losses associated with thermal load sharing technique. Also, since the system is comprised of two converters the losses are calculated for each converter and are represented by the aforementioned subscript notation followed by two numbers. For example the MOSFET transistor conduction losses in the current sharing case are denoted ' $\mathrm{P}_{\text {Conduction, Current }}=5.13 \mathrm{~W}$ and $2.30 \mathrm{~W}$ '. This indicates that the loss in converter 1 is $5.13 \mathrm{~W}$ and the loss in converter 2 is $2.30 \mathrm{~W}$. Also, as will be shown in Figure 12 and Figure 13 the notation $\mathrm{R}_{\mathrm{DS}(\mathrm{ON})+2.9 \mathrm{~m} \Omega}$ is adapted to indicate the difference in MOSFET transistor ON-resistance for the two transistors used in the test system. This value is found by comparing the actual measurements to the theoretical loss evaluations based on the nominal $\mathrm{R}_{\mathrm{DS}(\mathrm{ON})}$ value (transistor datasheet).

The MOSFET transistor conduction losses are found using the equations provided in [1]. Based on this approach the following set of loss curves can be established. 


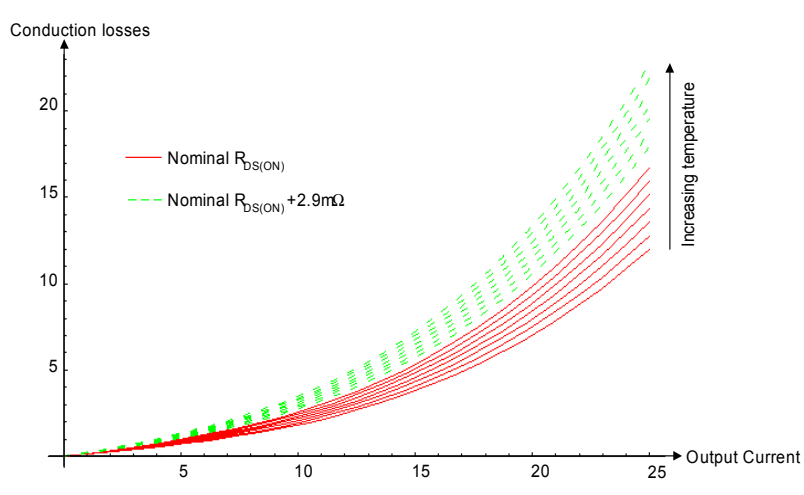

Figure 12 : Conduction losses vs. output current

Each curve in Figure 12 represents the conduction losses for a fixed temperature while varying the output current. This clearly shows that not only do the conduction losses increase as a function of output current but also as a function of temperature. The latter fact actually has a significant impact on the overall MOSFET losses. By relating the conduction losses at a given output current to the correct temperature based on heat-sink heat dissipation to the ambient the following results can be obtained:

$$
\begin{aligned}
& \mathrm{P}_{\text {Conduction, Current }}=5.13 \mathrm{~W} \text { and } 2.30 \mathrm{~W} \\
& \mathrm{P}_{\text {Conduction, Thermal }}=3.39 \mathrm{~W} \text { and } 2.92 \mathrm{~W}
\end{aligned}
$$

The process of determining the above losses and temperatures is successive, meaning that a change in one variable results in a change in the other variable. For this reason the curves shown in Figure 12 are established by calculating a number of points that relates output current, junction and heat-sink temperatures, MOSFET ON-resistance and total MOSFET power loss. Using the mathematical tool 'Mathematica' these points is then fitted to make up the curves shown in Figure 12.

MOSFET transistor switching losses is another heat generating factor that must be included in the overall MOSFET losses. These losses are found using the procedure provided in [2], from which the following graphical representation can be established:

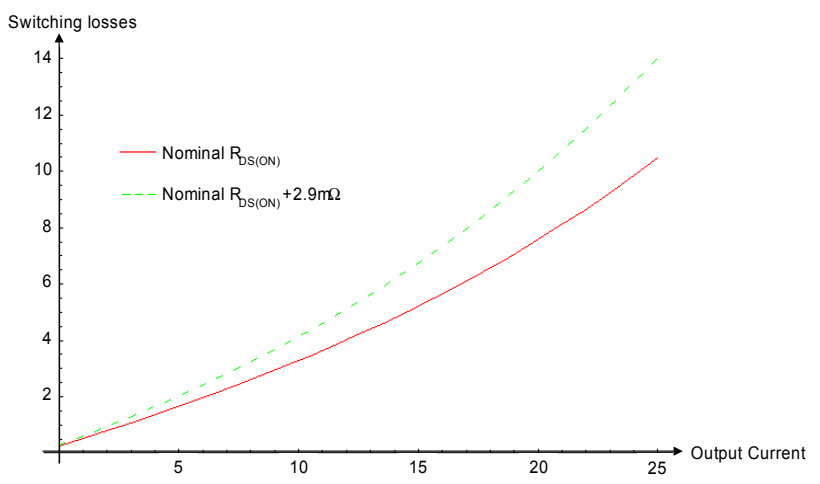

Figure 13 : Switching losses as a function of output current
It should be noted that the temperature dependency of the switching losses found in [3] have been interpolated and normalized to the switching losses at $25^{\circ} \mathrm{C}$ at an output current of $12.5 \mathrm{~A}$. Also, since the increase in current results in higher conduction losses the associated MOSFET transistor junction temperature increases. In turn, this increases the overall switching losses (as well as conduction losses) as a function of output current. This dependency is included in the switching loss curves shown in Figure 13. The overall effect of the redistribution of the load current gives the following result:

$$
\begin{aligned}
& \mathrm{P}_{\text {Switching, Current }}=5.65 \mathrm{~W} \text { and } 4.19 \mathrm{~W} \\
& \mathrm{P}_{\text {Switching, Thermal }}=4.47 \mathrm{~W} \text { and } 4.30 \mathrm{~W}
\end{aligned}
$$

The decrease in conduction losses amounts to $1.12 \mathrm{~W}$ while the switching losses contribute $1.07 \mathrm{~W}$ to the overall system loss reduction.

\section{Free-wheeling diodes}

The diode losses can be found using the simple equation shown below:

$$
\mathrm{P}_{\text {Diode }}=\mathrm{V}_{\text {static }} \cdot \mathrm{I}_{\text {Diode, avg }}+\mathrm{R}_{\text {Dynamic }} \cdot \mathrm{I}_{\text {Diode,RMS }}^{2}
$$

where $V_{\text {static }}$ is the forward voltage drop, $R_{\text {Dynamic }}$ is the inverse slope of the forward current vs. voltage drop. The parameters $I_{\text {Diode,avg }}$ and $I_{\text {Diode,RMs }}$ denote the average and RMS diode currents respectively and can be found using the following two equations:

$$
\begin{aligned}
\mathrm{I}_{\text {Diode avg }}=\mathrm{I}_{\text {Out }} \cdot(1-\mathrm{D}) & \mathrm{D}=\text { Duty-cycle } \\
\mathrm{I}_{\text {Diode,RMS }}=\sqrt{\mathrm{D} \cdot\left(\frac{\Delta \mathrm{I}_{\mathrm{L}}^{2}}{12}+\mathrm{I}_{\text {Out }}^{2}\right)} & \Delta \mathrm{I}_{\mathrm{L}}=\text { Inductor ripple }
\end{aligned}
$$

As will become apparent, the effect of the diode losses on the overall decrease in system power losses is much lower than that of the MOSFET transistors. One reason for this being that the forward voltage drop of a typical diode decreases with increasing temperature. However, the change in forward current also affects the forward voltage drop - with increasing forward voltage drop with increasing forward current. Being in close proximity to the MOSFET transistor heat-sinks the change in diode temperature is a combination of internal heating, heat transfer from the MOSFET transistors and a change in forward current. By taking these parameters into account the following values can be found:

$$
\begin{aligned}
& \mathrm{P}_{\text {Diode, Current }}=3.46 \mathrm{~W} \text { and } 4.44 \mathrm{~W} \\
& \mathrm{P}_{\text {Diode, Thermal }}=3.71 \mathrm{~W} \text { and } 3.86 \mathrm{~W}
\end{aligned}
$$

The overall decrease in diode losses amounts to $0.33 \mathrm{~W}$ 


\section{Current measurement resistors}

The relationship between current and power loss for this component is almost linear in the current range of interest to this paper. Thus, the gain in efficiency from redistributing the output current is negligible, which the following calculations will verify:

The total power loss in the current measurement resistors can be found using:

$$
\mathrm{P}_{\text {Resistor }}=\mathrm{I}_{\text {Out }}^{2} \cdot \mathrm{R}_{\text {Resistor }} \cdot \alpha
$$

where $\alpha$ denotes the temperature factor for copper. Inserting values for the load sharing scenarios gives the following results:

$$
\mathrm{P}_{\text {Resistor, Current }}=3.218 \mathrm{~W} \quad \mathrm{P}_{\text {Resistor, Thermal }}=3.224 \mathrm{~W}
$$

\section{Inductors}

The inductors are implemented using high flux powder cores from Magnetics. Since the shape of this component deviates from that of the current measurement resistors the correlation between temperature, wire resistance and DC power loss is no longer linear: The following equation for temperature estimation is used [5]:

$$
\text { Temperature Rise }\left({ }^{\circ} \mathrm{C}\right)=\left[\frac{\text { Total Power Loss }(\mathrm{mW})}{\text { Surface Area }\left(\mathrm{cm}^{2}\right)}\right]^{0.833}
$$

Inserting values in order to assess the copper and core losses gives the following result:

$$
\mathrm{P}_{\text {Inductor, Current }}=3.327 \mathrm{~W} \quad \mathrm{P}_{\text {Inductorl, Thermal }}=3.124 \mathrm{~W}
$$

The difference between these two losses accounts for a power loss decrease of $203 \mathrm{~mW}$. Like the current measurement resistors this loss decrease has only minor overall impact.

\section{Capacitors}

The last components that will be considered in this paper are the filter capacitors. On the assumption that the losses associated with these components are solely caused by the ripple current and the internal capacitor ESR the following total power loss can be found:

$$
\mathrm{P}_{\text {Capacitor, Current }}=4.511 \mathrm{~W} \quad \mathrm{P}_{\text {Capacitor, Thermal }}=4.019 \mathrm{~W}
$$

The equation used for determining the abovementioned capacitor losses is the same as that used for determining the losses in the current measurement resistors. The thermal load sharing causes an overall decrease in capacitor losses of $492 \mathrm{~mW}$.

\section{Summary}

Combining all the subtotals calculated above results in a total loss reduction of $3.21 \mathrm{~W}$. This decrease in system losses results in an overall efficiency increase by:

$$
\frac{\mathrm{P}_{\text {Out }}}{\mathrm{P}_{\text {Loss, thermal LS }}+\mathrm{P}_{\text {Out }}}-\frac{\mathrm{P}_{\text {Out }}}{\mathrm{P}_{\text {Loss, current LS }}+\mathrm{P}_{\text {Out }}}=1.6 \%
$$

This increase is approximately $0.4 \%$ lower than that indicated in Figure 10. However, additional losses due to changes in diode reverse recovery currents have not been included. Also, loss adjustments taking into account the difference in switching frequency have not been considered.

\section{RELIABILITY ASSESSMENT}

This section briefly introduces the reliability calculations that form the basis for the previously mentioned annual downtime. The point of origin is the Military Handbook 217F concerning reliability prediction of electronic equipment. Following the guidelines in this handbook and the general derivation techniques of finding analytical expressions for areas under a curve results in the following equation for $R(t)$ :

$$
\mathrm{R}(\mathrm{t})=1-\int_{0}^{\mathrm{t}} \mathrm{f}(\mathrm{t}) d t \Rightarrow \int_{\mathrm{t}}^{\infty} \mathrm{f}(\mathrm{t}) d t=\int_{\mathrm{t}}^{\infty} \lambda \cdot \mathrm{e}^{-\lambda \cdot \mathrm{t}} d t=\mathrm{e}^{-\lambda \cdot \mathrm{t}}
$$

This equation provides the probability of system survival within a given period of time $(\mathrm{t})$. In terms of annual down-time $\mathrm{R}(\mathrm{t})$ can be rearranged and expressed as:

$$
\mathrm{Q}(\mathrm{t})=\int_{0}^{\mathrm{t}} \mathrm{f}(\mathrm{t}) d t=\int_{0}^{\mathrm{t}} \lambda \cdot \mathrm{e}^{-\lambda \cdot \mathrm{t}} d t=1-\mathrm{e}^{-\lambda \cdot \mathrm{t}}
$$

In reliability engineering terms $\mathrm{Q}(\mathrm{t})$ is often referred to as the system unavailability, since it represents the probability of system failure.

In order to evaluate the overall system reliability a combined assessment equation for the $\mathrm{N}+1$ redundant system has to be established. This can be accomplished by combining the individual converter probabilities as shown next:

The total number of combinations is $2^{2}=4$ of which only 3 are valid for system success:

$$
\mathrm{R}_{\text {System }}=\mathrm{p}_{1} \cdot \mathrm{p}_{2}+\mathrm{q}_{1} \cdot \mathrm{p}_{2}+\mathrm{p}_{1} \cdot \mathrm{q}_{2}
$$

In the special case of identical probabilities this equation becomes:

$$
\mathrm{R}_{\text {System }}=\mathrm{p}^{2}+2 \cdot \mathrm{p} \cdot \mathrm{q}
$$


The latter equation can be used in the thermal load sharing situation since both converters operate at the same temperature, thus having the same failure rate.

Having established a theoretical foundation for the reliability assessment the next information needed is the temperatures of the individual components. This is a rather complicated task, for which reason the simplified thermal model shown in Figure 14 is used in all reliability calculations. This model shows the components in close proximity to the MOSFET transistors. Although additional components for the load sharing controller, the OP-amp etc. are present these are assumed to be operating at ambient temperature and are not affected by the change in heat-sink temperature.

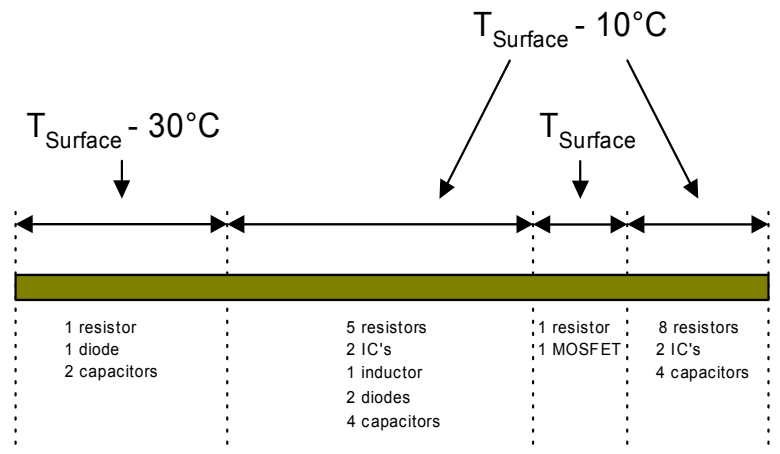

Figure $14:$ Simplified temperature distribution

Based on the temperature distribution in Figure 14 an average annual downtime of 10 minutes and 14 seconds is established (see Figure 1) for the current sharing technique. This number takes into account the redundancy concepts build into the power system. In other words the calculations indicate the probability of at least one working converter.

Reliability calculations for the thermal load sharing technique reveal that due to the redistribution of converter currents an annual downtime of 6 minutes and 11 seconds can be achieved. Compared to the results depicted in Figure 1 this is a reduction of almost $40 \%$.

A final verification of the thermal load sharing technique's advantages over the traditional current sharing technique is shown in Figure 15.

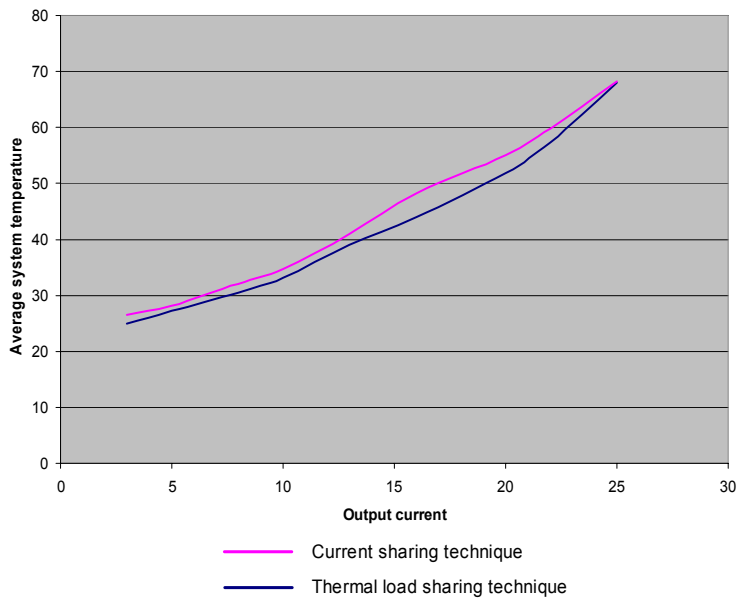

Figure 15 : Average system temperature
Figure 15 shows the average system temperature as a function of output current. It can be seen that the system operated by the thermal load sharing is at a constant lower temperature than its current sharing counterpart. At the extreme ends of the operating range the temperature difference between the two techniques is only $1{ }^{\circ} \mathrm{C}$ while the difference throughout the normal operating range is as high as $3.3^{\circ} \mathrm{C}$. This may not seem that impressive, but it should be noted that the temperatures depicted in Figure 15 are average temperatures meaning that the individual converter temperatures in the current sharing implementation varies by as much as $15^{\circ} \mathrm{C}$. A temperature difference of this magnitude lowers the converter reliability of the hotter converter considerably.

\section{CONCLUSION}

This paper has provided the experimental results of a realworld realization of the new thermal load sharing technique proposed in [1]. The results show that using the thermal load sharing technique not only increases the overall system reliability as calculated in [1] but also has a positive impact on the system efficiency. The increase in efficiency is achieved by redistributing the current supplied by each converter to obtain equal thermal conditions as opposed to the current sharing technique's intent to establish equal currents.

Further efficiency improvements are achievable if the current measurement resistors, not used by the thermal load sharing, are removed. However, for comparison purposes it was chosen to leave them in the circuit along with the OP-amps and the associated small-signal components.

\section{ACKNOWLEDGMENT}

The authors would like to thank Alcatel Space Denmark (ASD) for sponsoring this work, Senior Designer Henrik Møller from ASD for his contributions to the real-world implementation and Senior Design Engineer Arturo Arroyo from International Rectifier for helping with the temperature measurements.

\section{REFERENCES}

[1] Optimized load sharing control by means of thermal reliability management, Submitted for PESC2004

[2] Fundamentals of Power Electronics - second edition, Robert W. Erickson and Dragan Maksimovic

[3] Reliability challenges due to excess stress under high frequency switching of power devices, Professor Johann W. Kolar, ETH, Zürich

[4] Reliability prediction of electronic equipment, Military Handbook 217-F

[5] Magnetics core data for High Flux Powder Cores 